\title{
Imaging heterogeneous velocity structures and complex aftershock distributions in the source region of the 2007 Niigataken Chuetsu-oki Earthquake by a dense seismic observation
}

\author{
Aitaro Kato, Shinichi Sakai, Eiji Kurashimo, Toshihiro Igarashi, Takashi Iidaka, Naoshi Hirata, \\ Takaya Iwasaki, Toshihiko Kanazawa, and Group for the aftershock observations \\ of the 2007 Niigataken Chuetsu-oki Earthquake \\ Earthquake Research Institute, University of Tokyo, Tokyo, Japan
}

(Received December 4, 2007; Revised January 22, 2008; Accepted January 30, 2008; Online published November 18, 2008)

\begin{abstract}
The velocity structure and accurate aftershock distributions in the source region of the 2007 Niigataken Chuetsu-oki Earthquake (thrust type) are obtained by inverting the arrival times from 848 aftershocks observed by a dense seismic network deployed immediately after the mainshock ( $8 \mathrm{~h}$ later). Both the detailed velocity structure and the accurate aftershock distribution show lateral heterogeneity along the fault strike. In the northeast area, aftershocks are aligned along both the NW- and SE-dipping planes. These planes are conjugate to each other. The mainshock hypocenter is located close to the bottom of an approximately $50^{\circ} \mathrm{NW}$-dipping plane, which indicates that the mainshock rupture could have initiated on the NW-dipping plane. The high- $V_{p}$ body beneath this aftershock alignment shows a convex upward shape. In contrast, from the center to the southwest area, most of the aftershocks are aligned along SE-dipping planes. The high- $V_{p}$ body beneath this aftershock alignment shows a convex downward shape. Based on these results, we suggest that the crustal structure in the source region is divided into two segments by a boundary zone situated between the northeast and southwest areas. It should be noted that this segment boundary zone is coincident with the complex aftershock zone where numerous conjugate fault planes exist. We propose that the mainshock rupture initiated near the bottom of the NW-dipping fault plane and ran to the southwest, then transferred at the segment boundary zone which has numerous conjugate fault planes to the SE-dipping plane.
\end{abstract}

Key words: Tomography, the 2007 Niigataken Chuetsu-oki Earthquake, aftershocks, heterogeneous structures.

\section{Introduction}

On July 16, 2007, a shallow $M_{\mathrm{w}} 6.6$ earthquake occurred off-shore of the Chuetsu region in Niigata at 10:13 (Local time: $\mathrm{JST}=\mathrm{UT}+9 \mathrm{~h}$ ). This earthquake caused serious seismic damage in the surrounding areas, including liquefaction and landslides. Aftershocks were distributed offshore of the western edge of the Niigata basin with a strike of $\mathrm{N} 35^{\circ} \mathrm{E}$. The focal mechanism, as estimated by moment tensor inversion (the National Research Institute for Earth Science and Disaster Prevention, NIED), revealed a pure reverse fault with a strike of approximately $\mathrm{N} 35^{\circ} \mathrm{E}$ (Fig. 1). The dip angle of the mainshock fault was approximately $50^{\circ}$. This high-dip angle for a thrust-type event was unfavorably oriented in the direction of the regional maximum stress, which is almost horizontal to the WNW-ESE strike (Townend and Zoback, 2006). The focal mechanism was almost the same as that for the 2004 mid-Niigata Prefecture Earthquake, which occurred $30 \mathrm{~km}$ to the southeast of the 2007 earthquake. However, a significantly smaller number of aftershocks were induced by the latter (Japan Mete-

Copyright (c) The Society of Geomagnetism and Earth, Planetary and Space Sciences (SGEPSS); The Seismological Society of Japan; The Volcanological Society of Japan; The Geodetic Society of Japan; The Japanese Society for Planetary Sciences; TERRAPUB. orological Agency (JMA) catalog), with the largest aftershock $\left(M_{\mathrm{w}} 5.6\right)$ occurring on July 16 at $15: 37$ southeast of the mainshock hypocenter (Fig. 1).

The focal area was located within a thick MiocenePleistocene sedimentary basin (Niigata Basin) characterized by a NNE-SSW trending fault zone that forms topographic hills. Geological studies indicate that the thick sedimentary basin was formed in a rift structure with a normal fault system that developed during the extension stage of the Japan Sea. The normal fault system has subsequently been reactivated as a reverse fault system owing to a change in the tectonic stress regime from extension to compression that occurred around 3.5 Ma (e.g., Okamura, 1995). Surface folding has been well developed near the source region since then (Sato, 1994).

Based on the results of earlier studies of crustal structures in the source region of recent shallow large earthquakes along the Japan Sea coast, it has been suggested that complex structures associated with crustal stretching and uplift during the opening of the Japan Sea have the potential to nucleate mainshocks and trigger sequences of aftershocks (e.g., Kato et al., 2006, 2008). It is, therefore, of critical importance to image the complex seismogenic structures surrounding the source region and clarify their relationship to 


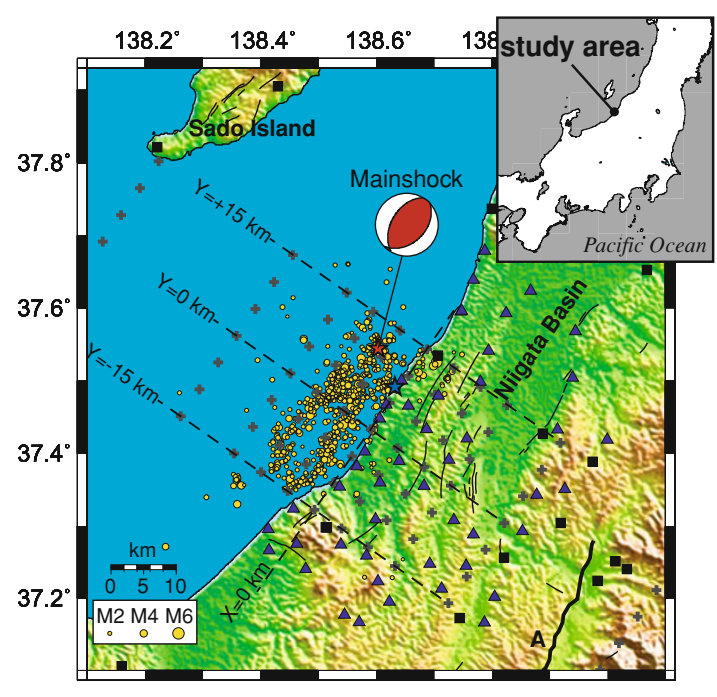

Fig. 1. Map of the relocated Niigataken Chuetsu-oki aftershocks determined by double-difference tomography, shown as yellow circles scaled to earthquake magnitude. The red star denotes the epicenter of the mainshock along with its moment tensor as determined by NIED. The blue star is the epicenter of the largest aftershock. Solid blue triangles and solid squares denote temporary seismic stations and permanent online stations, respectively. The grid used in the tomography is shown by gray crosses. Horizontal lines (broken lines) denote cross sections in Fig. 3. The surface trace of the Muikamachi-fault (A) is shown by thick solid line. The other major active faults are drawn as thin solid lines. Inset indicates the location of the present study area within central Honshu.

the rupture process (e.g., Thurber et al., 1995; Chiarabba et al., 1997). Furthermore, it is possible that aftershock distributions would be complex, consisting of several conjugate fault planes, similar to the aftershock sequence of the 2004 mid-Niigata Prefecture Earthquake (e.g., Hirata et al., 2005). Consequently, it is also necessary to elucidate accurate aftershock distributions.

While online seismic networks have been operated by the NIED, JMA, and universities in the source region, the average spacing of these stations (approx. $30 \mathrm{~km}$ ) is not sufficient for resolving detailed velocity structure and accurate aftershock distributions in the source region. Therefore, in order to accurately assess the velocity structure and aftershock distributions in and around the source region, we deployed an inland dense network of temporary seismic stations immediately after the 2007 Niigataken Chuetsu-oki Earthquake ( $8 \mathrm{~h}$ later). Forty-eight temporary seismic stations were deployed in the source region (Fig. 1). In this paper, we report our results from seismic tomography in and around the source region using this dataset and discuss the relationship between heterogeneous velocity structures and the earthquake generation process.

Although an ocean bottom seismographic deployment was conducted off-shore of the Chuetsu region (Shinohara et al., 2008), the observation started 10 days after the mainshock (from July 25 to August 28). Since there is a possibility that the aftershock distribution changed with elapsed time, it is important to analyze the inland data retrieved immediately after the mainshock to obtain a picture of the entire aftershock distribution. An integrated analysis using both inland and off-shore data will be reported in a future publication.

\section{Velocity Structure on the Mainshock Fault \\ 2.1 Data and method}

The seismic network used in the present study consisted of 48 three-component temporary stations, and 29 permanent online stations (NIED, JMA, Kyoto University, Kyusyu University, and University of Tokyo). These stations are located within a radius of about $70 \mathrm{~km}$ from the center of the source region (Fig. 1). Seismograms were continuously recorded at sampling rates of $100 \mathrm{~Hz}$ or $200 \mathrm{~Hz}$ between 18:25 (JST) July 16 (about $8 \mathrm{~h}$ after the mainshock) and August 30, immediately after the mainshock (about $8 \mathrm{~h}$ later). Both $P$ - and $S$-wave arrival times observed at the temporary and online stations were manually picked. The double-difference tomography method (Zhang and Thurber, 2003) was then applied to the arrival time data, which consisted of both absolute and differential arrival times. This method simultaneously solves for the three-dimensional $P$ and $S$-wave velocity structure $\left(V_{p}, V_{s}\right)$ and seismic event locations.

In this study, we used 848 well-determined aftershocks estimated from sufficient arrival time data; there were more than 15 and $10 P$ - and $S$-wave arrival times, respectively, for each event. The aftershocks are listed in the JMA catalog for the period between 18:25 July 16 (JST) and 17:25 August 29. The magnitude of most aftershocks selected for the tomography is greater than 1.5 .

The initial 848 hypocenter locations used for the tomography analysis were determined by applying a maximum likelihood estimation algorithm (Hirata and Matsu'ura, 1987) to the observed arrival times for two different onedimensional velocity structures with $V_{p} / V_{s}$ values of 1.73 (Fig. 2). Previous studies have revealed that the Niigata Basin area has remarkably low velocity layers at shallow depths less than $3 \mathrm{~km}$ (e.g., Takeda et al., 2004; Kato et al., 2006), while the eastern side of the Muikamachi-Fault or the Sado Island shows a moderate velocity structure. Furthermore, we adopted the station corrections, which were evaluated using average values of travel time residuals at each station, to locate the initial hypocenters before the tomography analysis.

The initial velocity structure used for the tomographic analysis is the same as that employed for the hypocenter determinations. The number of absolute $P$ - and $S$-wave arrival times used in the tomography is 39,594 and 36,548 , respectively, with the differential arrival times for the manually picked $P$ - and $S$-waves reaching 235,778 and 209,020, respectively. We also used the differential arrival times obtained by the waveform cross-correlation method in the time-domain (Schaff et al., 2004; Kato et al., 2006). The correlation measurements were conducted by aligning the nearest sample using $1.0 \mathrm{~s}$ window lengths beginning at $0.4 \mathrm{~s}$ before the manually picked arrival time and then computing the double-difference time to subsample precision using time-domain cross correlation. We were left with a dataset consisting of more accurate differential arrival times which contained 40,062 $P$-wave and 57,975 $S$-wave observations. These have a normalized cross-correlation coefficient exceeding 0.85 .

The grid nodes for the tomography analysis are located at $-300,-50,-25,-15,-10,-5,0,5,10,15,25,50$, 


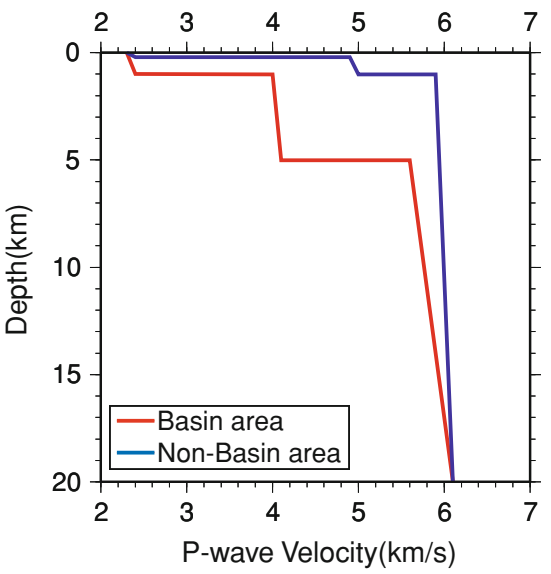

Fig. 2. Initial velocity structures used for the determination of initial hypocenters and the starting model of the tomography. The red line denotes the velocity structure for stations located within the Niigata Basin, while the blue line denotes that for stations outside of the basin.

and $300 \mathrm{~km}$ on the $X$-axis $\left(\mathrm{N} 125^{\circ} \mathrm{E}\right.$; perpendicular to the fault strike); $-300,-60,-15,-10,-5,0,5,10,15,60$, and $300 \mathrm{~km}$ on the $Y$-axis $\left(\mathrm{N} 35^{\circ} \mathrm{E}\right) ;-150,0,3,6,9,12$, $15,20,25$, and $300 \mathrm{~km}$ on the $Z$-axis (depth) (Fig. 1). Different smoothing weights of $5,10,15$, and 30 were tested. The main features of these models are very similar in the regions with good ray coverage. Taking the trade-off between the roughness and the stabilization of the model into consideration (Zhang and Thurber, 2003), we chose the model using weight 10 as our preferred model. The weighted root mean square (RMS) travel time residual was reduced from $0.222 \mathrm{~s}$ to $0.061 \mathrm{~s}$ after 20 iterations.

\subsection{Results}

We evaluated the model resolution using the following synthetic test. A checkerboard velocity model on the mainshock fault plane was created from the initial velocity structure using perturbations of $\pm 5 \%$. Synthetic travel times were then calculated for this checkerboard model, with uniformly-distributed random noise ranging from $-0.025 \mathrm{~s}$ to $0.025 \mathrm{~s}$ for the $P$-wave and from $-0.05 \mathrm{~s}$ to $0.05 \mathrm{~s}$ for the $S$-wave. Synthetic data were subsequently inverted using the initial velocity structure as a starting model. The unmasked areas in the cross sections of Fig. 3 correspond to the areas where the inverted synthetic model shows good recovery of the assumed anomalies for $P$ - and $S$-wave structures. $P$-wave or $S$-wave velocity anomalies were well recovered in the areas where the density of the aftershocks is high. Although the resolution of the $V_{s}$ structure is lower than that for $V_{p}$, the general spatial distributions of $V_{s}$ are similar to those of $V_{p}$. Given the limitations in $V_{s}$ resolution, interpretations presented in this paper will focus mainly on the $V_{p}$ structure.

From Fig. 1, we found that epicentral distributions are fairly heterogeneous along the fault strike. The mainshock epicenter is located at the northeast edge of the aftershock region $(Y \sim+10 \mathrm{~km})$ where the density of aftershocks is moderate. However, aftershocks are highly concentrated in the southwest between $Y=+2$ and $Y=+6 \mathrm{~km}$. From the center to the southwest $(-10 \leq Y \leq+2 \mathrm{~km})$, the epicenters divide into two lineaments parallel to the coastline. At
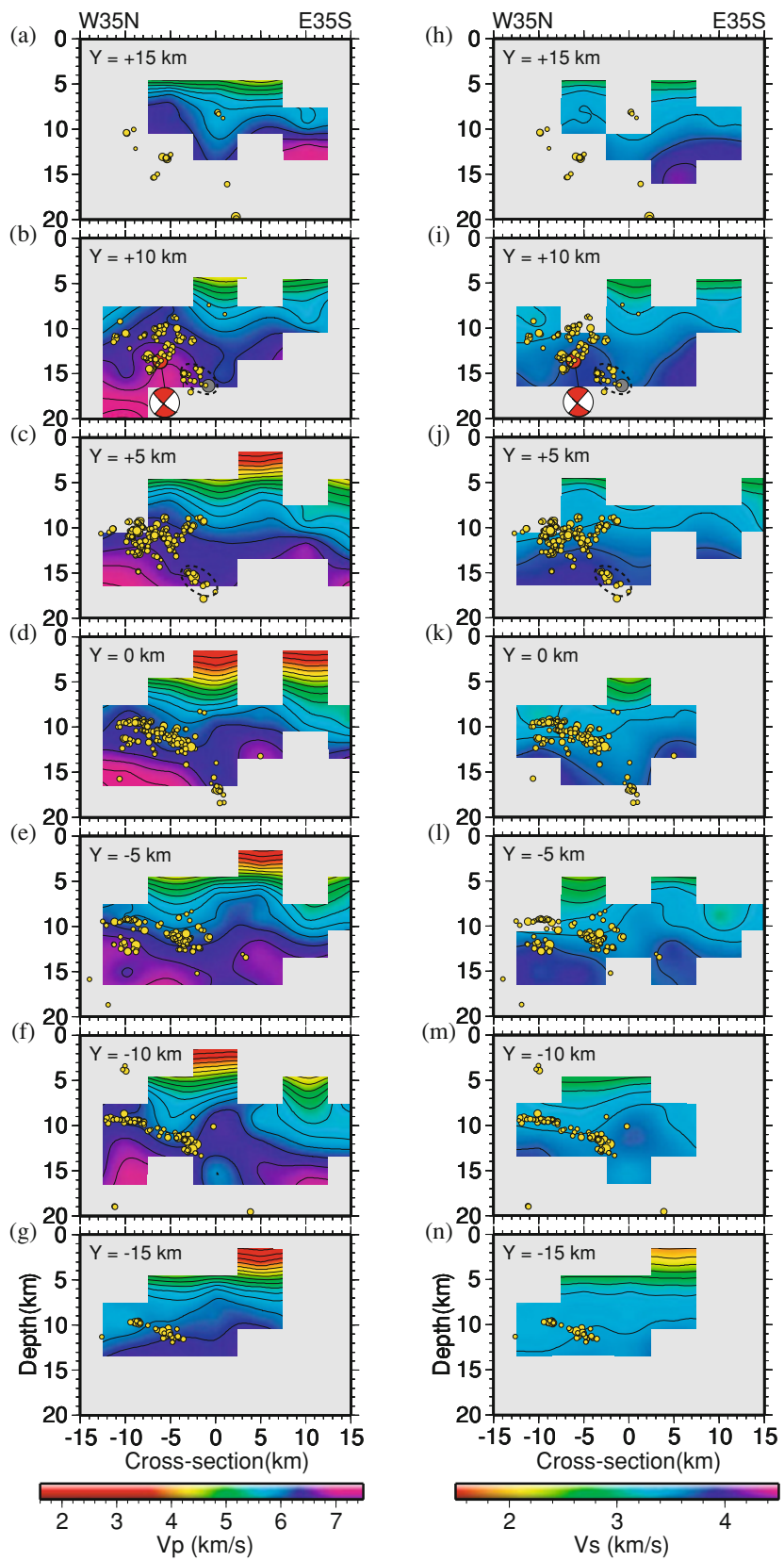

Fig. 3. Depth sections through the $V_{p}((\mathrm{a})-(\mathrm{g}))$ and $V_{s}$ model ((h)-(n)) with superimposed relocated aftershocks distributed within $\pm 2.5 \mathrm{~km}$ of each line. Depth sections ordered from NE to SW for each model $(Y=$ $+15,+10,+5,0,-5,-10,-15)$. The white-masked areas correspond to low model resolution. The contour line interval is $0.25 \mathrm{~km} / \mathrm{s}$. Mainshock hypocenter is shown as a red circle with the moment tensor solution (NIED) projected on the section using a backward hemisphere projection. The largest aftershock hypocenter is denoted by a gray circle, and the secondary aftershocks are encircled by black dashed ellipses.

the southwest edge $(Y \sim-15 \mathrm{~km})$, these two lineaments of epicenters appear to merge again. Note that there is an obvious seismic gap, like a "seismicity hole", at the southwest areas (from $Y=0$ to $Y=-10 \mathrm{~km}$ ).

Figure 3 shows the $V_{p}$ and $V_{s}$ structures along seven cross sections perpendicular to the fault strike, superimposed with relocated aftershocks within $\pm 2.5 \mathrm{~km}$ from the section. Both the velocity structure and the aftershock distribution show lateral heterogeneity along the fault strike. Based on the aftershock distributions of $Y=+5$ and $+10 \mathrm{~km}$, after- 
shocks are aligned along both NW- and SE-dipping planes. These planes are conjugate to each other and are extensively distributed. Aftershock distributions are highly complex, especially at $Y=+5 \mathrm{~km}$, consisting of numerous conjugate fault planes. The mainshock hypocenter is located close to the bottom of an approximately $50^{\circ} \mathrm{NW}$-dipping plane $(Y=+10 \mathrm{~km})$, which corresponds to one nodal plane of the mainshock focal mechanism (NIED). Secondary aftershocks induced by the largest aftershock are located to the east and have a depth deeper than that of the mainshock; they are aligned on an approximately $40^{\circ} \mathrm{SE}$-dipping plane (dashed ellipses in $Y=+5,+10 \mathrm{~km}$ of Fig. 3). In contrast, on the cross sections of $Y \leq 0 \mathrm{~km}$, most of the aftershocks are aligned along the SE-dipping planes. On the cross sections of $Y=-5$ and $-10 \mathrm{~km}$, the SE-dipping planes are clearly divided by the seismic gap mentioned above. Note that average depths of aftershocks to the northeast are deeper than those to the southwest.

Based on the velocity structure (Fig. 3), most aftershocks occurred at depths where $V_{p}$ is greater than $6.0 \mathrm{~km} / \mathrm{s}$. Some of these appear to be aligned roughly along velocity boundaries. On the cross section of $Y=+10 \mathrm{~km}$ close to the mainshock hypocenter, it is interesting to note that a high$V_{p}$ body greater than $6.25 \mathrm{~km} / \mathrm{s}$ shows a convex upward shape in the aftershock area. NW-dipping aftershocks associated with the mainshock rupture are distributed along the top edge of the western slope of the convex upward high$V_{p}$ body (at the depth of around $15 \mathrm{~km}$ ). The secondary aftershocks induced by the largest aftershock appear to be aligned along the top edge of the opposite eastern slope of this high- $V_{p}$ body. In contrast, on the cross sections of $Y$ $\leq 0 \mathrm{~km}$, a high- $V_{p}$ body greater than $6.25 \mathrm{~km} / \mathrm{s}$ shows a convex downward shape. It appears that some aftershocks in the southwest areas are aligned roughly along a velocity boundary dipping to the SE (from $Y=-10$ to $0 \mathrm{~km}$ ).

Figure 4 reveals that the $V_{p}$ structure at a depth of $12 \mathrm{~km}$ sharply changes between the cross sections of $Y=0$ and

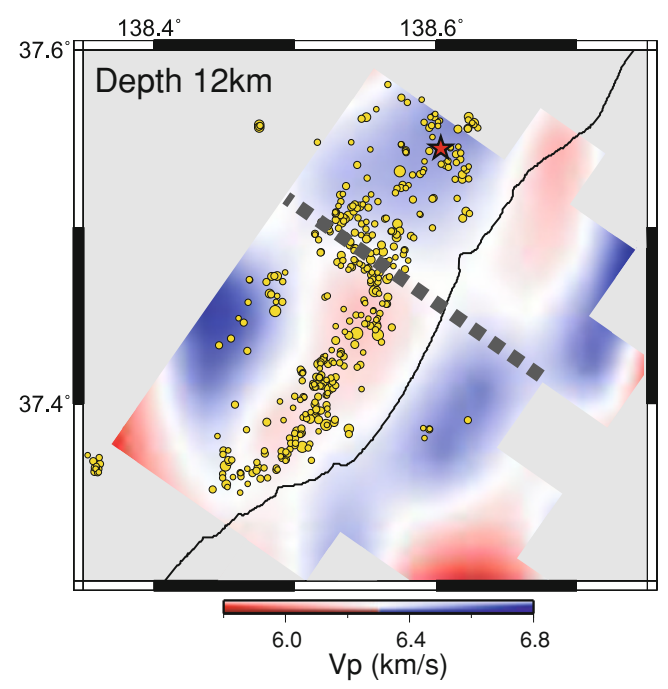

Fig. 4. Map view of $V_{p}$ structure at the depth of $12 \mathrm{~km}$ with superimposed relocated aftershocks distributed at depths from $10.5 \mathrm{~km}$ to $13.5 \mathrm{~km}$. The red star denotes the epicenter of the mainshock hypocenter. Thick broken line shows an approximate location of the segment boundary zone.
$=+5 \mathrm{~km}$ (broken line in the figure). Off-shore velocities are slightly higher near the mainshock hypocenter than in the surrounding area. On the other hand, the off-shore velocities near the coastline have lower values from the center to the southwest.

\section{Discussion}

We consider that low velocity layers ( $V_{p}$ is less than $5.5 \mathrm{~km} / \mathrm{s}$ ) at shallow depths correspond to soft sediments that have accumulated in a rift system formed by crustal stretching during the opening of the Japan Sea (e.g., Sato,
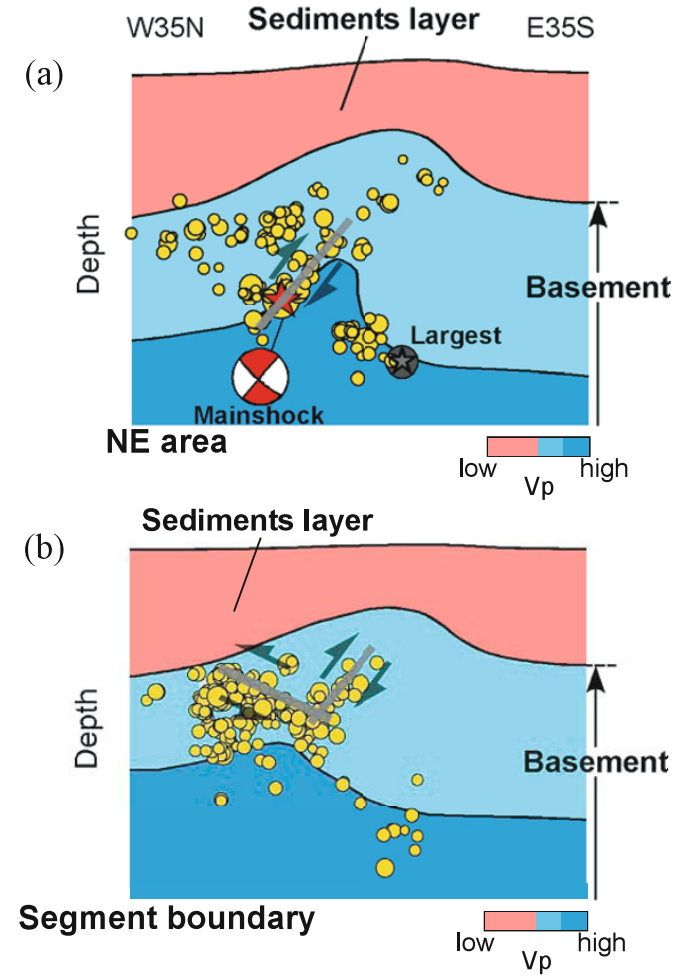

(c)

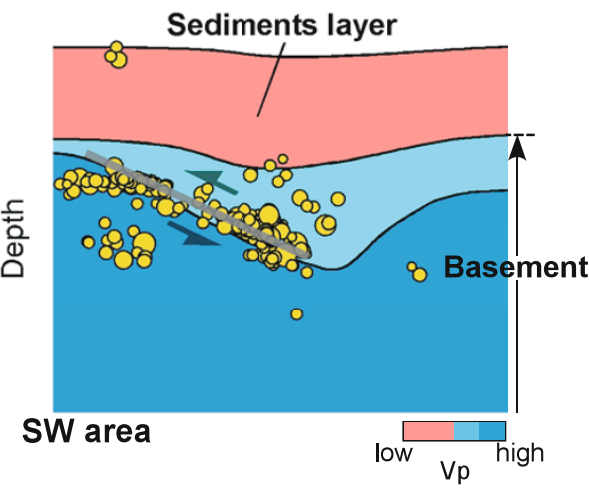

Fig. 5. Schematic images of the major heterogeneous structures in the source region. Color code shows a scale of $P$-wave velocity. Transparent gray lines denote the fault planes estimated from the aftershock distributions for the mainshock rupture. Transparent arrows show a slip direction for each fault plane. (a) At the northeast area $(Y \sim+10 \mathrm{~km})$ with the relocated aftershocks (yellow circles scaled to earthquake magnitude) between $Y=+6$ and $Y=+15 \mathrm{~km}$. The red and gray stars indicate hypocenters of the mainshock and the largest aftershock. The moment tensor solution for the mainshock (NIED) is projected on the section. (b) At the segment boundary zone $(Y \sim+5 \mathrm{~km})$ with the relocated aftershocks from $Y=+1$ to $+6 \mathrm{~km}$. (c) At the southwest area $(Y$ $\sim-5 \mathrm{~km}$ ) with the relocated aftershocks between $Y=-12.5$ and $Y=$ $-2.5 \mathrm{~km}$. 
1994; Okamura et al., 1995). Most of the aftershocks occurred at depths where $V_{p}$ is greater than $6.0 \mathrm{~km} / \mathrm{s}$, suggesting that most of the aftershocks occurred in the basement beneath the sediment layers. This situation is significantly different from that identified in the source region of the 2004 mid-Niigata Prefecture Earthquake, where most of the aftershocks associated with the mainshock rupture are aligned along the NW-dipping boundary between the sediments and the basement (e.g., Kato et al., 2006).

Some aftershocks appear to be aligned roughly along velocity boundaries in the basement (Fig. 3). This result implies that the occurrence of the mainshock rupture could be influenced by heterogeneous structures in the basement. Several large aftershocks that followed the 2004 mid-Niigata Prefecture Earthquake also occurred along the velocity boundaries imaged in the basement (Kato et al., 2006). It should be noted that crustal stretching and shortening that has occurred along the Japan coastline has created heterogeneous crustal structures that could affect the seismic activities around the study area.

The results of our study demonstrate that both velocity structure and the aftershock distribution vary along the fault strike. We summarized the features of the velocity structure and aftershock distribution in a schematic figure (Fig. 5). The mainshock hypocenter is located close to the bottom of an approximately $50^{\circ} \mathrm{NW}$ dipping plane $(Y=+10 \mathrm{~km}$ in Fig. 3). This indicates that the mainshock rupture could initiate on the NW-dipping plane with a dimension of $8 \mathrm{~km}$ (length) $\times 8 \mathrm{~km}$ (width). However, from the center to the southwest $(Y \leq+1 \mathrm{~km})$, aftershocks are aligned along the SE-dipping plane with a dimension of $16 \mathrm{~km}$ (length) $\times$ $12 \mathrm{~km}$ (width). These results suggest that dip-directions of aftershock planes associated with the mainshock rupture change around the cross-section of $Y=+5 \mathrm{~km}$ (length approx. $5 \mathrm{~km}$ ) (Aoki et al., 2008), where many conjugate fault planes are defined (Fig. 5(b)).

Near the mainshock hypocenter, the high- $V_{p}$ body beneath the aftershock alignment shows a convex upward shape (Fig. 5(a)). On the other hand, the high- $V_{p}$ body beneath the aftershock alignment shows a convex downward shape from the center to the southwest area (Fig. 5(c)). We therefore suggest that the crustal structure in the source region is divided into two segments by a boundary zone situated between the northeast area and southwest one with an azimuth perpendicular to the fault strike (Fig. 4). It is notable that this segment boundary zone is coincident with the complex aftershock zone where numerous conjugate fault planes exist ( $Y=+5 \mathrm{~km}$ in Fig. 3). Furthermore, an extension of this segment boundary to the inland roughly corresponds to an area where several surface traces of active faults (Research Group for Active Faults of Japan, 1991) and fold axes (Geological Survey of Japan, 2002) rotate counterclockwise from the strike $\mathrm{N} 35^{\circ} \mathrm{E}-\mathrm{S} 35^{\circ} \mathrm{W}$ to the N$S$ (Figs. 1 and 4). A lateral heterogeneity of the velocity structure and aftershock distribution along the fault strike have been observed in a similar fold-thrust belt (Chiarabba et al., 1997).

Waveform analyses of the source rupture process show that the mainshock rupture propagated to the southwest from the hypocenter (Koketsu et al., 2007; Takenaka et al.,
2007; Nozu, 2008). Given these considerations, we propose that the mainshock rupture initiated near the bottom of the approximately $50^{\circ} \mathrm{NW}$-dipping fault plane and ran to the southwest. The rupture then transferred to the SEdipping plane in the segment boundary zone with numerous conjugate fault planes at a depth shallower than that of the mainshock hypocenter. The rupture was able to propagate along the velocity boundaries in the basement because of a relative mechanical weakness. Indeed, several previous studies reported that successive or simultaneous ruptures occurred on two conjugate fault planes (e.g., Robinson et al., 2001; Horikawa, 2001). It is a scientifically interesting question whether the dynamic rupture can transfer to a conjugate fault plane from its original plane. In future work, we need to investigate if this is possible by using a numerical simulation of nonplanar dynamic rupture propagation (e.g., Aochi and Fukuyama, 2002). As an alternative approach, however, it may be worth considering the possibility of simultaneous ruptures on both the NW- and SEdipping planes.

\section{Conclusions}

We obtained the velocity structure and accurate aftershock distributions of the 2007 Niigataken Chuetsu-oki Earthquake by inverting the arrival times from 848 aftershocks observed by a dense seismic network deployed immediately after the mainshock. Both the detailed velocity structure and the accurate aftershock distribution show lateral heterogeneity along the fault strike. At the northeast area, aftershocks are aligned along both NW- and SEdipping planes. These planes are conjugate to each other. The mainshock hypocenter is located close to the bottom of an approximately $50^{\circ} \mathrm{NW}$-dipping plane, which indicates that the mainshock rupture could have initiated on the NWdipping plane. The high- $V_{p}$ body beneath this aftershock alignment shows a convex upward shape. In contrast, from the center to the southwest area, most of the aftershocks are aligned along the SE-dipping planes. The high- $V_{p}$ body beneath this aftershock alignment shows a convex downward shape. We thus suggest that the crustal structure in the source region is divided into two segments by the boundary zone situated between the northeast area and southwest one. It should be noted that this segment boundary zone is coincident with the complex aftershock zone where numerous conjugate fault planes exist.

Acknowledgments. We thank H. Zhang for use of the tomoDD code. We also thank T. Haneda, M. Kobayashi, S. Watanabe, I. Ogino, M. Saka, M. Serizawa and K. Miyakawa for the data acquisition. We are grateful to Y. Okamura, C. Chiarabba, and D. Okaya for their constructive comments, which led to substantial improvement to the original manuscript. We thank the National Research Institute for Earth Science and Disaster Prevention, Japan Meteorological Agency, for allowing us to use the waveform data collected at each online station. Most of the figures were created using GMT (Wessel and Smith, 1995). This research was partially supported by the Ministry of Education, Science, Sports and Culture (MEXT), Grant-in-Aid for Special Purposes, 19900003, 2007, and the Special Coordination Funds for the Promotion of Science and Technology (MEXT) under the title of an urgent research for the 2007 Chuetsu-oki Earthquake. The work is conducted as a part of the 2nd new program of research and observation for earthquake prediction (2004 to 2008). 


\section{References}

Aochi, H. and E. Fukuyama, Three-dimensional nonplanar simulation of the 1992 Landers earthquake, J. Geophys. Res., 107(B2), 2035, 10. 1029/2000JB000061, 2002.

Aoki, Y., M. Furuya, and T. Kato, Coseismic deformation due to the 2007 Chuetsu-oki earthquake $\left(M_{\mathrm{w}}=6.8\right)$, Earth Planets Space, 60, this issue, 1075-1080, 2008

Chiarabba, C., A. Amato, and M. Meghraoui, Tomographic images of the EI Asnam fault zone and the evolution of a seismogenic thrust-related fold, J. Geophys. Res., 102, 24485-24498, 1997.

Geological Survey of Japan, AIST, Geological map of Japan, CD-ROM Version, Digital Geoscience Map G-3, 2002.

Hirata, N. and M. Matsu'ura, Maximum-likelihood estimation of hypocenter with origin time eliminated using nonlinear inversion technique, Phys. Earth Planet. Inter., 47, 50-61, 1987.

Hirata, N., H. Sato, S. Sakai, A. Kato, and E. Kurashimo, Fault system of the 2004 Mid Niigata Prefecture Earthquake and its aftershocks, Landslides, 2, 153-157, 2005.

Horikawa, H., Earthquake doublet in Kagoshima, Japan: Rupture of asperities in a stress shadow, Bull. Seismol. Soc. Am., 91, 112-127, 2001.

Kato, A., S. Sakai, N. Hirata, E. Kurashimo, T. Iidaka, T. Iwasaki, and T. Kanazawa, Imaging the seismic structure and stress field in the source region of the 2004 mid-Niigata prefecture earthquake: Structural zones of weakness and seismogenic stress concentration by ductile flow, $J$. Geophys. Res., 111, B08308, doi:10.1029/2005JB004016, 2006.

Kato, A., S. Sakai, T. Iidaka, T. Iwasaki, E. Kurashimo, T. Igarashi, N. Hirata, T. Kanazawa, and Group for the aftershock observations of the 2007 Noto Hanto Earthquake, Three-dimensional velocity structure in the source region of the Noto Hanto Earthquake in 2007 imaged by a dense seismic observation, Earth Planets Space, 60, 105-110, 2008.

Koketsu, K., H. Miyake, and K. Hikima, Source Inversion for the 2007 Chuetsu-oki, Japan, Earthquake: A Case of Difficulty Determining the Source Fault Plane, Eos Trans. AGU, 88(52), Fall Meet. Suppl., Abstract, S54A-05, 2007.

Nozu, A., Rupture Process of the 2007 Chuetsu-oki, Niigata, Japan, Earthquake-Waveform Inversion using Empirical Green's Functions-, Earth Planets Space, 2008 (in press).

Okamura, Y., M. Watanabe, R. Morijiri, and M. Satoh, Rifting and basin inversion in the eastern margin of the Japan Sea, The Island Arc, 4, 166$81,1995$.

Research Group for Active Faults of Japan, Active faults in Japan: Sheet maps and inventories, 437 pp., The University of Tokyo Press, 1991.
Robinson, D. P., C. Henry, S. Das, and J. H. Woodhouse, Simultaneous Rupture Along Two Conjugate Planes of the Wharton Basin Earthquake, Science, 292, 1145-1148, 2001.

Sato, H., The relationship between late Cenozoic tectonic events and stress field and basin development in northeast Japan, J. Geophys. Res., 99, 22261-22274, 1994.

Schaff, P. D., G. H. R. Bokelmann, W. L. Ellsworth, E. Zanzerkia, F Waldhauser, and G. C. Beroza, Optimizing Correlation Techniques for Improved Earthquake Location, Bull. Seismol. Soc. Am., 94, 705-721, 2004

Shinohara, M., T. Kanazawa, T. Yamada, K. Nakahigashi, S. Sakai, R. Hino, Y. Murai, A. Yamazaki, K. Obana, Y. Ito, K. Iwakiri, R. Miura, Y. Machida, K. Mochizuki, K. Uehira, M. Tahara, A. Kuwano, S. Amamiya, S. Kodaira, T. Takanami, Y. Kaneda, and T. Iwasaki, Precise aftershock distribution of the 2007 Chuetsu-oki Earthquake obtained by using an ocean bottom seismometer network, Earth Planets Space, 60 , this issue, 1121-1126, 2008.

Takeda, T., H. Sato, T. Iwasaki, N. Matsuta, S. Sakai, T. Iidaka, and A. Kato, Crustal structure in the northern Fossa Magna region, central Japan, modeled from refraction/wide-angle reflection data, Earth Planets Space, 56, 1293-1299, 2004.

Takenaka, H., Y. Yamamoto, and H. Yamasaki, High-Resolution Source Imaging of the 2007 Niigataken Chuetsu-oki Earthquake From Dense Strong-Motion Networks: Focus on the First 5 Seconds of the Rupture Process, Eos Trans. AGU, 88(52), Fall Meet. Suppl., Abstract, S31A0208, 2007.

Thurber, C. H., S. R. Atre, and D. Eberhart-Phillips, Three-dimensional $V_{p}$ and $V_{p} / V_{s}$ structure of the Loma Prieta, California, from local earthquake tomography, Geophys. Res. Lett., 22, 3079-3082, 1995.

Townend, J. and M. D. Zoback, Stress, strain, and mountain building in central Japan, J. Geophys. Res., 111, B03411, doi:10.1029/ 2005JB003759, 2006

Wessel, P. and W. H. F. Smith, New version of the generic mapping tools released, Eos Trans. AGU, 76, 329, 1995.

Zhang, H. and C. H. Thurber, Double-difference tomography: The method and its application to the Hayward fault, California, Bull. Seismol. Soc. Am., 93, 1875-1889, 2003.

A. Kato (e-mail: akato@eri.u-tokyo.ac.jp), S. Sakai, E. Kurashimo, T. Igarashi, T. Iidaka, N. Hirata, T. Iwasaki, T. Kanazawa, and Group for the aftershock observations of the 2007 Niigataken Chuetsu-oki Earthquake 